\title{
Assessing the Clinical Benefit of Systemic Adjuvant Therapies for Early Breast Cancer
}

\author{
Bestimmung des klinischen Nutzens systemischer adjuvanter \\ Therapien beim frühen Mammakarzinom
}

\author{
Authors \\ Volker Möbus ${ }^{1}$, Susanne Hell ${ }^{2}$, Marcus Schmidt ${ }^{3}$ \\ Affiliations \\ 1 Klinik für Gynäkologie und Geburtshilfe, \\ Klinikum Frankfurt-Höchst, Frankfurt, Germany \\ 2 Roche Pharma AG, Grenzach-Wyhlen, Germany \\ 3 Klinik und Poliklinik für Geburtshilfe und Frauen- \\ gesundheit, Universitätsmedizin Mainz, Mainz, Germany
}

Key words

early breast cancer, adjuvant therapy, clinical benefit

Schlüsselwörter

frühes Mammakarzinom, adjuvante Therapie, klinischer Nutzen

$\begin{array}{ll}\text { received } & 8.6 .2017 \\ \text { revised } & 8.9 .2017 \\ \text { accepted } & 11.9 .2017\end{array}$

Bibliography

DOI https://doi.org/10.1055/s-0043-119542

Geburtsh Frauenheilk 2017; 77: 1079-1087 @ Georg Thieme

Verlag KG Stuttgart · New York | ISSN 0016-5751

Correspondence

Prof. Dr. med. Volker Möbus

Klinik für Gynäkologie und Geburtshilfe,

Klinikum Frankfurt-Höchst

Gotenstraße 6-8, 65929 Frankfurt a. M., Germany

volker.moebus@KlinikumFrankfurt.de

$\Theta$

Deutsche Version unter:

https://doi.org/10.1055/s-0043-119542

\section{ABSTRACT}

Oncologic therapy is currently undergoing significant changes. A number of innovative targeted medications currently in clinical development have raised high expectations. With that in mind, discussions about terms such as "clinical benefit" and "clinical relevance" are highly topical. This also applies to further developments in the field of adjuvant systemic therapies for early-stage breast cancer. As the treatment aim is curative, assessment of the clinical benefit of adjuvant therapies must be largely based on efficacy outcomes. The focus must be on improving disease-free survival rates and lowering the risk of recurrence. Because of the current low mortality rates, statements about overall survival rates are only possible after very long observation periods. Consequently, new drugs in adjuvant therapies should be considered as offering a clinical benefit, if they reduce the risk of recurrence below current low levels of risk. The evidence for established adjuvant therapy standards in early-stage breast cancer can be used as objective criteria for comparison. This review article considers the requirements for clinical benefit of new adjuvant therapies for early breast cancer, based on examples from adjuvant endocrine therapy, adjuvant polychemotherapy and adjuvant anti-HER2 therapy.

\section{ZUSAMMENFASSUNG}

Die onkologische Therapie befindet sich im Umbruch. Hohe Erwartungen sind mit einer Reihe innovativer zielgerichteter Medikamente verknüpft, die sich derzeit in der klinischen Entwicklung befinden. Vor diesem Hintergrund erfahren Diskussionen um die Begriffe klinischer Nutzen oder klinische Relevanz neue Aktualität. Dies gilt auch für die Weiterentwicklungen der adjuvanten systemischen Therapie des frühen Mammakarzinoms. In Anbetracht der kurativen Zielsetzung erfolgt die Beurteilung des klinischen Nutzens einer adjuvanten Therapie maßgeblich anhand von Wirksamkeitsendpunkten. Der Fokus liegt hierbei auf Verbesserungen des krankheitsfreien Überlebens und des Rezidivrisikos. Eine Aussage zum Gesamtüberleben ist aufgrund der heute erreichten niedrigen Mortalitätsraten erst nach sehr langen Beobachtungszeiten möglich. Folgerichtig sollte neuen Medikamenten für die adjuvante Therapie ein klinischer Nutzen zugesprochen werden, wenn sie eine weitere Reduktion des Rezidivrisikos über den heutigen hohen Standard hinaus ermöglichen. Die Evidenz für etablierte adjuvante Therapiestandards beim frühen Mammakarzinom kann als objektiver Maßstab zum Vergleich herangezogen werden. Am Beispiel der adjuvanten endokrinen Therapie, der adjuvanten Polychemotherapie und der adjuvanten Anti-HER2-Therapie werden in diesem Übersichtsartikel die Anforderungen für den klinischen Nutzen neuer adjuvanter Therapien beim frühen Mammakarzinom abgeleitet. 


\section{Introduction}

In the wake of the recent rapid advances in molecular biology, oncology therapy is currently undergoing major changes, moving towards treatment geared to the individual tumor biology. The new targeted therapies need to be benchmarked against existing therapy options which are already available. Bearing this in mind and in view of the cost of these innovations, the discussion about the terms clinical benefit and clinical relevance has become highly topical. This is demonstrated by the fact that scientific societies such as the American Society of Clinical Oncology (ASCO) and the European Society of Medical Oncology (ESMO) are working to develop criteria which can be used to assess the clinical benefits of new medications [1,2].

The question of clinical relevance is currently also an issue when assessing recent developments in adjuvant systemic therapy for early breast cancer. Two phase III studies have reported positive results for new targeted drugs used in systemic adjuvant therapy to treat early HER2-positive breast cancer, i.e. there was a significant improvement in the primary study endpoint "diseasefree survival" $[3,4]$. Adjuvant studies with CDK4/6 inhibitors and immune checkpoint inhibitors have been launched or are in the final discussion stages of compiling their study protocols [5-11]. But how can the clinical benefit of an adjuvant therapy to treat early breast cancer be measured? Which improvements resulting from the new therapy should be classified as clinically relevant?

This review article discusses the issue of clinical relevance with regard to adjuvant therapies for early breast cancer. The discussion looks at examples from the evidence for various established adjuvant therapy standards. This study deliberately chose not to focus on individual studies but instead to look at large meta-analyses and the findings on recurrence rates and overall mortality rates, similar to the approach used by ASCO, ESMO and the European and American regulatory authorities EMA and FDA [12,13].

\section{Systemic Therapy of Early Breast Cancer - Rationale and Medical Need}

Today, breast cancer is viewed as a generalized systemic disease. Systemic therapy is consequently an integral part of the treatment of patients with early breast cancer [14-19]. The goal of this approach is to eliminate micro-metastases which are already present in the early stages of disease and thereby to prevent recurrence and increase the probability of cure $[20,21]$. The results of neoadjuvant chemotherapy administered before primary surgery and adjuvant chemotherapy administered after surgery are comparable in terms of overall survival. Because of this, the AGO recommends considering neoadjuvant administration for patients with an indication for chemotherapy [18].

The relative 10-year survival of women with breast cancer is now $82 \%$. Overall, the mortality rates for breast cancer have dropped continually since the 1990s; nevertheless it remains a health issue in Germany [22]. In 2013, 71640 women in Germany developed breast cancer and 17853 women died of it. The Robert Koch Institute anticipates that there will be 77600 new cases of breast cancer in Germany in 2020 [22].
Despite the many successes, the above-mentioned figures show that there is still a real medical need to improve systemic therapies for patients with early breast cancer.

A good example for this is HER2-positive early breast cancer. Adjuvant therapy with trastuzumab for 1 year resulted in a clear and significant improvement in disease-free survival (DFS) (hazard ratio $[\mathrm{HR}]=0.60 ; 95 \%$ confidence interval $[\mathrm{Cl}]$ : $0.50-0.71$, $\mathrm{p}<0.00001)$ and in overall survival (OS) $(\mathrm{HR}=0.66 ; 95 \% \mathrm{Cl}$ : 0.57-0.77, $p<0.00001)$ for patients with HER2-positive early breast cancer [23]. However, after 10 years $25-31 \%$ of women who had received adjuvant therapy with trastuzumab in the studies used to obtain approval of the drug went on to develop recurrence, in two thirds of cases in the form of distant metastasis. Up to $19 \%$ of patients participating in the study had died during the follow-up period of 10 years [24-26]. In the pivotal studies NCCTG 9831/NSABP B-31, BCIRG 006 and HERA, depending on the mean follow-up time, the percentage of deaths from breast cancer ranged from $72 \%$ after 8.3 years, to $83 \%$ after 10.3 years to $91 \%$ after 11.0 years (relative to the total number of deaths in the therapy arms of the respective safety populations) [27].

\section{Standards for Adjuvant Systemic Therapy}

Endocrine therapy, polychemotherapy and anti-HER2 therapy are undisputed standard therapies for adjuvant systemic therapy. Whether treatment is administered alone, sequentially or in combination depends on the subtype and on the risk factors [14-19].

\section{Adjuvant endocrine therapy}

Adjuvant endocrine therapy is indicated for patients with hormone receptor-positive breast cancer [17-19]. This therapeutic principle was first introduced for tamoxifen. In the meta-analysis by the Early Breast Cancer Trialists' Group (EBCTCG) published in 1998, the effect of trastuzumab was investigated using the individual patient data of 37000 women from 55 studies. After excluding data from 8000 so-called ER-poor patients with no or low ER expression ( $<10 \mathrm{fmol} / \mathrm{mg}$ cytosolic protein), a 5-year therapy regimen with tamoxifen showed a proportional reduction in the risk of recurrence by $47 \%$ and a reduction in mortality risk of $26 \%$ [28]. A subsequent meta-analysis by the EBCTCG using individual data from 10386 women with ER-positive disease reported absolute improvements after 5, 10 and 15 years with 5 years of adjuvant tamoxifen therapy. For the whole population the recurrence rates were $11.4,13.6$ and $11.8 \%$, and the mortality rates were 3.5 , 7.6 and $7.9 \%$, respectively ( $\bullet$ Table 1 ) [29]. With the same relative reduction of risk of $39 \%$, tamoxifen therapy in lymph node-positive patients resulted in higher absolute improvements than for lymph node-negative patients: $16.1 \%$ after 5 years compared to $9.1 \%$ [29].

Treatment with aromatase inhibitors, which is recommended for the endocrine therapy of postmenopausal women, is another development in adjuvant endocrine therapy. Therapy options include the administration of aromatase inhibitors over a period of 5 years and therapy with different sequences of tamoxifen and aromatase inhibitors (2-3 years of tamoxifen followed by aromatase inhibitors for a total period of 5 years; $2-3$ years of aromatase inhibitors followed by tamoxifen for a total period of 5 years; 
- Table 1 Relative and absolute reduction in the risk of recurrence and mortality for early breast cancer following adjuvant endocrine therapy [28,29].

\begin{tabular}{|c|c|c|c|c|c|c|c|c|c|c|c|}
\hline \multirow{3}{*}{$\begin{array}{l}\text { Inter- } \\
\text { vention }\end{array}$} & \multirow{3}{*}{$\begin{array}{l}\text { Patients } \\
\text { (n) }\end{array}$} & \multicolumn{5}{|c|}{ Recurrence } & \multicolumn{5}{|c|}{ Mortality } \\
\hline & & \multicolumn{2}{|c|}{ After 5 years } & \multicolumn{2}{|c|}{ After 10 years } & \multirow{2}{*}{$\begin{array}{l}\text { Relative risk } \\
(95 \% \mathrm{Cl})\end{array}$} & \multicolumn{2}{|c|}{ After 5 years } & \multicolumn{2}{|c|}{ After 10 years } & \multirow{2}{*}{$\begin{array}{l}\text { Relative risk } \\
(95 \% \mathrm{Cl})\end{array}$} \\
\hline & & Rate & $\begin{array}{l}\text { Absolute } \\
\text { difference }\end{array}$ & Rate & $\begin{array}{l}\text { Absolute } \\
\text { difference }\end{array}$ & & Rate & $\begin{array}{l}\text { Absolute } \\
\text { difference }\end{array}$ & Rate & $\begin{array}{l}\text { Absolute } \\
\text { difference }\end{array}$ & \\
\hline \multicolumn{12}{|c|}{ Tamoxifen (Tam) vs. no endocrine therapy (ET) [28] } \\
\hline NoET & \multirow[t]{2}{*}{10386} & $26.5 \%$ & \multirow[t]{2}{*}{$-11.4 \%$} & $38.3 \%$ & \multirow[t]{2}{*}{$-13.6 \%$} & & $13.9 \%$ & \multirow[t]{2}{*}{$-3.5 \%$} & $30.7 \%$ & \multirow[t]{2}{*}{$-7.6 \%$} & \\
\hline $\begin{array}{l}5 \text { years of } \\
\text { Tam }\end{array}$ & & $15.1 \%$ & & $24.7 \%$ & & & $10.4 \%$ & & $23.1 \%$ & & \\
\hline \multicolumn{12}{|c|}{ Aromatase inhibitor (Al) vs. tamoxifen [29] } \\
\hline $\begin{array}{l}5 \text { years of } \\
\text { Tam }\end{array}$ & \multirow[t]{2}{*}{9885} & $12.1 \%$ & \multirow[t]{2}{*}{$-3.1 \%$} & $22.7 \%$ & \multirow[t]{2}{*}{$-3.6 \%$} & \multirow[t]{2}{*}{$\begin{array}{l}0.80 \\
(0.73-0.88)\end{array}$} & $9.4 \%$ & \multirow[t]{2}{*}{$-1.2 \%$} & $24 \%$ & \multirow[t]{2}{*}{$-2.7 \%$} & \multirow[t]{2}{*}{$\begin{array}{l}0.89 \\
(0.8-0.97)\end{array}$} \\
\hline 5 years of $\mathrm{Al}$ & & $9.0 \%$ & & $19.1 \%$ & & & $8.2 \%$ & & $21.3 \%$ & & \\
\hline $\begin{array}{l}5 \text { years of } \\
\text { Tam }\end{array}$ & \multirow[t]{2}{*}{11798} & $12.1 \%$ & \multirow[t]{2}{*}{$-2.6 \%$} & $19.0 \%$ & \multirow[t]{2}{*}{$-2.0 \%$} & \multirow[t]{2}{*}{$\begin{array}{l}0.82 \\
(0.75-0.91)\end{array}$} & $8.8 \%$ & \multirow[t]{2}{*}{$-1.7 \%$} & $17.5 \%$ & \multirow[t]{2}{*}{$-2.9 \%$} & \multirow[t]{2}{*}{$\begin{array}{l}0.82 \\
(0.73-0.91)\end{array}$} \\
\hline $\begin{array}{l}2-3 \text { years of } \\
\text { Tam } \rightarrow \text { Al } \\
\text { up to year } 5\end{array}$ & & $9.5 \%$ & & $17.0 \%$ & & & $7.1 \%$ & & $14.6 \%$ & & \\
\hline
\end{tabular}

5 years of tamoxifen followed by 5 years of aromatase inhibitors) $[17,18]$. The standard duration of therapy is 5 years. An extended therapy regimen with aromatase inhibitors after 5 years of endocrine therapy may be administered after an individual analysis of the risks and benefits [18].

The additional effect of aromatase inhibitors compared to tamoxifen was investigated in a meta-analysis by the EBCTCG published in 2015 and based on the data of 31920 women from 9 studies. Compared to 5 years of adjuvant therapy with tamoxifen, the 5 -year therapy with aromatase inhibitors showed a relative reduction of the risk of recurrence by $20 \%$ and of the mortality risk by $11 \%$. The absolute improvement in the rate of recurrence was $3.1 \%$ after 5 years and $3.6 \%$ after 10 years, and the absolute improvement in mortality rate was $1.2 \%$ and $2.7 \%$, respectively $(\vee$ Table 1) [30]. The sequence tamoxifen for $2-3$ years followed by aromatase inhibitor therapy up until the end of year 5 showed a relative reduction in the risk of recurrence and in the mortality risk of $18 \%$, respectively, compared to 5 years of adjuvant tamoxifen therapy. The absolute improvement in recurrence rates was $2.6 \%$ after 5 years and $2.0 \%$ after 10 years, and the absolute improvement in mortality rates was 1.7 and $2.9 \%$, respectively ( $\triangleright$ Table 1 ) [30].

If the relative reduction of risk was the same for various subgroups, absolute improvements depended on the existing constellation of risk factors. The 5 -year recurrence rate decreased, in absolute terms, by $1.2 \%$ for patients with node-negative disease, by $3.7 \%$ for patients with $1-3$ positive lymph nodes and by $6.4 \%$ for women with more than 4 affected lymph nodes [30].

Another meta-analysis investigated the effect of aromatase inhibitors on postmenopausal women using published study data. Meta-analysis found significant benefits for DFS (HR $=0.70 ; 95 \%$ Cl: $0.63-0.77)$ and $\mathrm{OS}(\mathrm{HR}=0.81 ; 95 \% \mathrm{Cl}: 0.71-0.93)$ after 5 years of adjuvant sequential therapy with tamoxifen followed by an aromatase inhibitor compared to 5 years of adjuvant therapy with ta- moxifen. The same analysis reported a significant benefit for DFS $(\mathrm{HR}=0.62 ; 95 \% \mathrm{Cl}: 0.52-0.74)$ but no benefit for $\mathrm{OS}(\mathrm{HR}=0.87$; $95 \% \mathrm{Cl}: 0.66-1.16)$ for extended therapy with aromatase inhibitors after 5 years of therapy with tamoxifen [31].

\section{Adjuvant chemotherapy}

Chemotherapy is an option to treat early-stage breast cancer with the exception of low-risk patients with HER2-negative hormone receptor-positive disease $[14,15,18]$. According to the German S3-guideline, adjuvant chemotherapy is indicated for HER2-positive tumors, non-endocrine sensitive tumors or when the tumor's endocrine sensitivity is unclear, lymph node-positive disease, grade 3 tumors and for patients aged $<35$ years [17].

Several meta-analyses have shown that polychemotherapy significantly improves both the rate of recurrence and overall survival. The meta-analyses found a significant relative reduction of risk, irrespective of patient age, lymph node status, tumor size, tumor differentiation, estrogen receptor status or adjuvant treatment with tamoxifen $[18,19,22]$. Absolute benefits differed for patients with high absolute risk compared with patients with low absolute risk $[28,29,32]$.

The introduction of a combination of cyclophosphamide, methotrexate and 5-fluorouracil (CMF) marked the start of adjuvant polychemotherapy [33]. The effect of this combination was analyzed in detail in the EBCTCG meta-analysis published in 2012, which was based on the individual data of 100000 patients. The recurrence risk for patients who received standard doses of CMF chemotherapy decreased proportionally by $30 \%$ compared to patients who did not receive adjuvant chemotherapy. The absolute improvement in recurrence rates was $9.9 \%$ after 5 years and $10.2 \%$ after 10 years. The mortality risk decreased proportionally by $16 \%$, with absolute improvements of 2.7 and $4.7 \%$ respectively after 5 and 10 years ( $\bullet$ Table 2 ) [32]. 
- Table 2 Relative and absolute reduction in recurrence risk and mortality risk of patients with early breast cancer who received adjuvant polychemotherapy [30].

\begin{tabular}{|c|c|c|c|c|c|c|c|c|c|c|c|}
\hline \multirow{3}{*}{$\begin{array}{l}\text { Inter- } \\
\text { vention }\end{array}$} & \multirow{3}{*}{$\begin{array}{l}\text { Patients } \\
\text { (n) }\end{array}$} & \multicolumn{5}{|c|}{ Recurrence } & \multicolumn{5}{|c|}{ Mortality } \\
\hline & & \multicolumn{2}{|c|}{ After 5 years } & \multicolumn{2}{|c|}{ After 10 years } & \multirow{2}{*}{$\begin{array}{l}\text { Relative risk } \\
(95 \% \mathrm{Cl})\end{array}$} & \multicolumn{2}{|c|}{ After 5 years } & \multicolumn{2}{|c|}{ After 10 years } & \multirow{2}{*}{$\begin{array}{l}\text { Relative risk } \\
(95 \% \mathrm{Cl})\end{array}$} \\
\hline & & Rate & $\begin{array}{l}\text { Absolute } \\
\text { difference }\end{array}$ & Rate & $\begin{array}{l}\text { Absolute } \\
\text { difference }\end{array}$ & & Rate & $\begin{array}{l}\text { Absolute } \\
\text { difference }\end{array}$ & Rate & $\begin{array}{l}\text { Absolute } \\
\text { difference }\end{array}$ & \\
\hline \multicolumn{12}{|c|}{ Chemotherapy vs. no chemotherapy } \\
\hline No chemo & \multirow{2}{*}{$\begin{array}{l}5253 \\
(N+34 \%)\end{array}$} & $30.2 \%$ & \multirow[t]{2}{*}{$-9.9 \%$} & $39.8 \%$ & \multirow[t]{2}{*}{$-10.2 \%$} & \multirow{2}{*}{$\begin{array}{l}0.70 \\
(0.63-0.77)\end{array}$} & $16.4 \%$ & \multirow[t]{2}{*}{$-2.7 \%$} & $30.7 \%$ & \multirow[t]{2}{*}{$-4.7 \%$} & \multirow{2}{*}{$\begin{array}{l}0.84 \\
(0.76-0.93)\end{array}$} \\
\hline $\begin{array}{l}\text { Standard } \\
\text { CMF }\end{array}$ & & $20.3 \%$ & & $29.6 \%$ & & & $13.7 \%$ & & $26.0 \%$ & & \\
\hline \multicolumn{12}{|c|}{ Anthracycline (A) vs. CMF } \\
\hline $\begin{array}{l}\text { Standard } \\
\text { CMF }\end{array}$ & \multirow[t]{2}{*}{$\begin{array}{l}5122 \\
(N+61 \%)\end{array}$} & $32.9 \%$ & \multirow[t]{2}{*}{$-0.5 \%$} & $42.1 \%$ & \multirow[t]{2}{*}{$-1.1 \%$} & \multirow[t]{2}{*}{$\begin{array}{l}0.99 \\
(0.90-1.08)\end{array}$} & $22.4 \%$ & \multirow[t]{2}{*}{$-0.6 \%$} & $34.6 \%$ & \multirow[t]{2}{*}{$-1.2 \%$} & \multirow[t]{2}{*}{$\begin{array}{l}0.97 \\
(0.89-1.07)\end{array}$} \\
\hline $\begin{array}{l}\text { Standard } \\
4 A C\end{array}$ & & $32.4 \%$ & & $41.0 \%$ & & & $21.8 \%$ & & $33.4 \%$ & & \\
\hline CMF & \multirow{2}{*}{$\begin{array}{l}9527 \\
(N+53 \%)\end{array}$} & $25.5 \%$ & \multirow[t]{2}{*}{$-3.2 \%$} & $33.8 \%$ & \multirow[t]{2}{*}{$-2.6 \%$} & \multirow{2}{*}{$\begin{array}{l}0.89 \\
(0.82-0.96)\end{array}$} & $15.7 \%$ & \multirow[t]{2}{*}{$-2.9 \%$} & $27.1 \%$ & \multirow[t]{2}{*}{$-3.9 \%$} & \multirow{2}{*}{$\begin{array}{l}0.84 \\
(0.76-0.92)\end{array}$} \\
\hline $\begin{array}{l}\text { A higher cu- } \\
\text { mulative } \\
\text { dose }\end{array}$ & & $22.3 \%$ & & $31.2 \%$ & & & $12.8 \%$ & & $23.2 \%$ & & \\
\hline \multicolumn{12}{|c|}{ Taxane ( $\mathrm{T})+$ anthracycline vs. anthracycline } \\
\hline & & \multicolumn{2}{|c|}{ After 5 years } & After 8 & & & After 5 & & After 8 & & \\
\hline$A($ more $A)$ & 33084 & $22.0 \%$ & $-2.8 \%$ & - & - & 0.86 & $12.4 \%$ & $-1.2 \%$ & - & - & 0.90 \\
\hline TA & $(N+82 \%)$ & $19.2 \%$ & & - & & $(0.82-0.91)$ & $11.2 \%$ & & - & & $(0.84-0.97)$ \\
\hline A (same A) & 11167 & $27.3 \%$ & $-3.6 \%$ & $34.8 \%$ & $-4.6 \%$ & 0.84 & $18.2 \%$ & $-1.9 \%$ & $26.7 \%$ & $-3.2 \%$ & 0.86 \\
\hline TA & $(\mathrm{N}+100 \%)$ & $23.7 \%$ & & $30.2 \%$ & & $(0.78-0.91)$ & $16.3 \%$ & & $23.5 \%$ & & $(0.79-0.93)$ \\
\hline
\end{tabular}

C: cyclophosphamide, M: methotrexate, F: 5-fluorouracil, N+: lymph node-positive patients

Adjuvant polychemotherapy first improved with the introduction of anthracyclines. This development was also analyzed in the EBCTCG meta-analysis of 2012. An anthracycline-based regimen consisting of doxorubicin and cyclophosphamide (AC) was not found to be more effective than standard CMF ( $>$ Table 2 ). When higher-cumulative-dose anthracycline-based regimens were compared with CMF, the meta-analysis showed a relative reduction of $11 \%$ for the risk of recurrence. The absolute improvement in recurrence rates was $3.2 \%$ after 5 years and $2.6 \%$ after 10 years compared to CMF. This translated as a relative reduction in mortality risk of $16 \%$ and an absolute improvement in the mortality rate of $2.9 \%$ after 5 years and $3.9 \%$ after 10 years ( $\triangleright$ Table 2 ) [32].

The addition of taxanes represent another step forward for adjuvant polychemotherapy. Anthracycline- and taxane-based chemotherapy regimens are now a standard component of adjuvant systemic therapy [14-19].

Several meta-analyses have investigated the value of taxanes using published and aggregated outcomes, and came to similar results regarding the relative reduction of recurrence risk and mortality risk [34-38]. Examples include the results of the Cochrane meta-analysis which looked at 12 studies with a total of 21191 patients. The Cochrane analysis found a significant improvement in DFS ( $\mathrm{HR}=0.81 ; 95 \% \mathrm{Cl}: 0.77-0.86)$ and $\mathrm{OS}$ $(\mathrm{HR}=0.81 ; 95 \% \mathrm{Cl}: 0.75-0.88)$ for taxane-based adjuvant regimens compared to non-taxane-based adjuvant regimens. The analysis did not identify any subgroups which benefitted more or less from the adjuvant administration of taxanes [35].

The 2012 EBCTCG meta-analysis investigated the effect of taxanes based on individual patient data. According to this analysis, the additional administration of a taxane after combination therapy with anthracycline led to a relative reduction in the recurrence risk of $16 \%$ and a relative reduction in the mortality rate of $14 \%$ compared to the same anthracycline therapy without additional taxane administration. The absolute improvement in recurrence rates was $3.6 \%$ after 5 years and $4.6 \%$ after 8 years; the absolute improvement in mortality rate was $1.9 \%$ after 5 years and $3.2 \%$ after 8 years. When taxane-anthracycline combinations were compared with anthracycline regimens where the number of cycles in the control arm was increased as a counterbalance, the relative reduction in the recurrence risk was $14 \%$ and the relative reduction in the mortality risk was $10 \%$. The absolute improvement in recurrence rate was $2.8 \%$ after 5 years and the improvement in mortality rate was $1.2 \%$ ( $\bullet$ Table 2 ) [32]. Compared to the results in this meta-analysis for patients who did not receive adjuvant chemotherapy, modern anthracycline- and taxanebased chemotherapy regimens achieved an absolute improvement in the recurrence rates of $10.9 \%$ after 5 years and $17.2 \%$ after 10 years and an absolute improvement in the mortality rates of 6.8 and $16.1 \%$, respectively [32]. 


\section{Adjuvant anti-HER2 therapy}

According to the current clinical therapy guidelines, adjuvant therapy with trastuzumab for 1 year is indicated for patients with HER2-positive early breast cancer. For patients with node-negative disease, the indication is defined according to tumor size: some guidelines recommend adjuvant therapy with trastuzumab for tumor diameters $>5 \mathrm{~mm}[15,16,18]$, and all guidelines recommend adjuvant therapy with trastuzumab for tumors with diameters of $1 \mathrm{~cm}$ and above [15-18].

Adjuvant targeted anti-HER2 therapy was introduced with trastuzumab. There are a number of meta-analyses on the effect of anti-HER2 therapy, but none of them are yet based on individual patient data. The meta-analyses all found significant increases in DFS and OS after adjuvant anti-HER2 therapy with trastuzumab [39-41]. The Cochrane meta-analysis was the most comprehensive analysis, comprising 8 studies on early HER2-positive breast cancer. According to the Cochrane analysis, the relative reduction in recurrence risk was $40 \%$ (HR for DFS $=0.60 ; 95 \% \mathrm{Cl}: 0.50-0.71$ ) and the relative reduction in mortality risk was 34\% (HR for OS $=0.66$; $95 \% \mathrm{Cl}: 0.57-0.77$ ) for trastuzumab-containing regimens compared to regimens without trastuzumab [23]. The meta-analysis provided no data on absolute improvement rates. In drug approval studies, the improvement in DFS was reported to be $5.9-9 \%$ after 5 years and $5.1-11.5 \%$ after 10 years, and the improvement in OS was $2.4-5 \%$ after 5 years and $4.6-8.8 \%$ after 10 years $[24-26,42,43]$.

\section{Escalation and de-escalation of adjuvant systemic therapy}

Dose-dense chemotherapy, which represents an escalation of adjuvant systemic therapy, clearly shows that the magnitude of the additional benefit achieved with a new adjuvant therapy depends on the patient's baseline risk. Dose-dense chemotherapy is the therapy of choice for a high-risk subpopulation of patients with early breast cancer and large tumor burden [18]. Currently there are only meta-analyses based on published data [44-46] which consistently show a benefit for dose-dense chemotherapy compared to conventional chemotherapy. The most extensive analysis with a total of 17188 patients from 8 studies reported a relative reduction of recurrence risk by $16 \%(\mathrm{HR}(\mathrm{DFS})=0.84 ; 95 \% \mathrm{Cl}$ : $0.77-0.91)$ and a reduction of the mortality risk by $14 \%$ (HR $(O S)=0.86$; $95 \% \mathrm{Cl}: 0.79-0.93$ ) [46]. The risk profiles of the investigated study populations differed. Individual studies which included patients with a particularly high baseline risk showed a greater benefit for patients [47]. The German ETC study only included patients with more than 4 positive lymph nodes $[48,49]$. The risk of recurrence after 5 and 10 years for these women treated with dose-dense chemotherapy decreased proportionally compared to conventional chemotherapy by $28 \%$ and $26 \%$, respectively. This corresponds to a benefit in absolute terms of $8 \%$ and $9 \%$, respectively. Patients' mortality risk after 5 and 10 years had decreased proportionally by $24 \%$ and $28 \%$, respectively; this corresponds to an absolute improvement of $5 \%$ and $10 \%$, respectively $[48,49]$.

It is important to mention that de-escalation of systemic therapy is discussed and even recommended for specific subgroups of patients with early breast cancer and a very low risk of recurrence
$[14,18]$. In a large phase II study, in which patients with HER2positive early breast cancer, negative lymph node status and tumor diameters $<3 \mathrm{~cm}$ received deescalated chemotherapy (i.e. only paclitaxel in combination with trastuzumab without additional anthracyclines), the 7-year rate for DFS was $93.3 \%(95 \% \mathrm{Cl}$ : 90.4-96.2\%), the breast-cancer specific survival rate was $98.6 \%$ (95\% Cl: $97.0-100 \%)$. Only $1 \%$ of patients developed distant recurrence [50].

\section{Multigene signatures}

A number of multigene signatures have been developed which aim to identify those patients with early breast cancer whose prognosis is so favorable that it is worth discussing whether chemotherapy might be dispensed with [51]. According to the recommendations of the AGO, methodologically standardized and clinically validated multigene tests could be useful for women with hormone receptor-positive, HER2-negative, node-negative early breast cancer as the findings could be used to support decisions for or against adjuvant chemotherapy when conventional prognostic parameters including $\mathrm{Ki}-67$ do not support a definitive decision [18]. This recommendation was based on data from large prospective/retrospective studies and the initial results of prospective studies [52-67]. In one study, the 3-year DFS of patients with early, hormone receptor-positive, HER2-negative breast cancer and a low recurrence score (RS) $\leq 11$ who received endocrine therapy alone was $98 \%$ even without adjuvant chemotherapy [65]. Another study reported a DFS of $93.8 \%$ and an OS of $98 \%$ after 5 years for patients with hormone receptor-positive, HER2negative, lymph node-negative tumors and a low RS (<11) following endocrine therapy alone [66].

\section{Tools to Assess Clinical Benefit in Oncology}

Defining the term clinical benefit in the context of therapies for early breast cancer is currently a challenge.

There are a number of different national institutions which systematically assess health-relevant technologies. They include the National Institute for Health and Care Excellence (NICE) in the United Kingdom, the Haute Autorité de Santé (HAS) in France and the Gemeinsamer Bundesausschuss (G-BA, Federal Joint Committee) supported by the Institut für Qualität und Wirtschaftlichkeit (IQWiG, Institute for Quality and Efficiency in Healthcare) in Germany. NICE appraises therapies to obtain standardized health economic assessment measures such as QALY (quality-adjusted life years) and ICER (incremental cost-effectiveness ratio), which are independent of specific indications [68]. After considering the severity of disease, efficacy, adverse events, therapeutic value compared with other available therapies, and public health benefits, HAS assesses the actual clinical benefit of therapies by first categorizing them as insufficient or sufficient, then rating the benefit as "low", "moderate" or "substantial". HAS also assesses therapies for their clinical added value based on their comparative efficacy and safety, rating the clinical added value as either "major", "substantial", "moderate", "minor" or "no improvement". The parameters determining classification into the individual categories are not described [69]. The IQWiG provides concrete thresholds in the form of the upper limit of the $95 \%$ confi- 
High clinical benefit

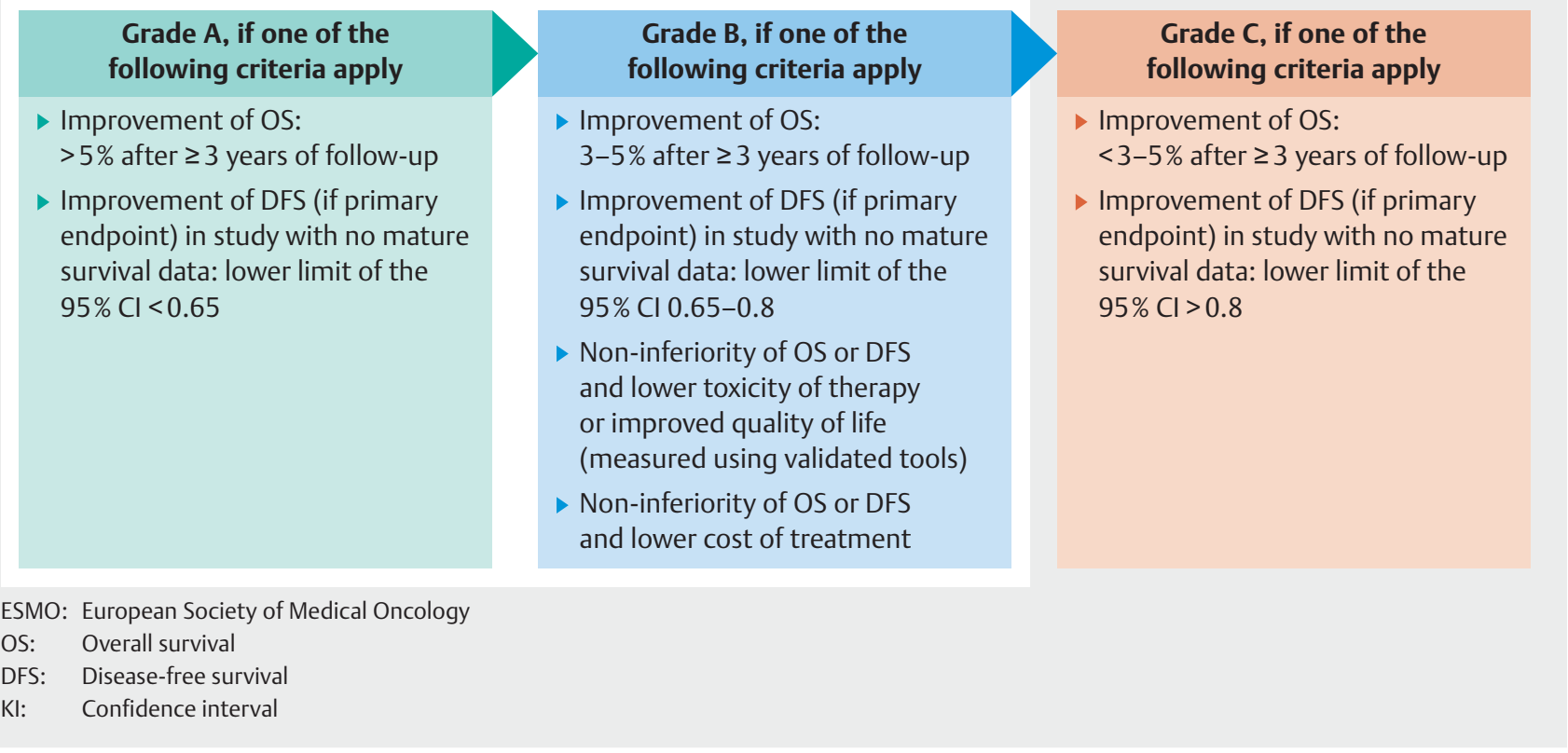

- Fig. 1 ESMO Medical Oncology Magnitude of Clinical Benefit Scale (MCBS): assessment criteria for new adjuvant, neoadjuvant and potentially curative therapies [2].

dence interval for the relative risk, using figures obtained to assess the extent of the additional benefit for the categories "mortality", "morbidity", "health-related quality of life" and "adverse events". The additional benefit achieved in each of these categories may be rated as major (overall mortality $<0.85$; severe symptoms, adverse events and quality of life $>0.75$ ), considerable (overall mortality < 0.95 ; severe symptoms, adverse events and quality of life $>0.90$; non-severe symptoms and adverse events $<0.80$ ), minor (overall mortality $<1.00$; severe symptoms, adverse events and quality of life > 1.00; non-severe symptoms and adverse events $<0.90$ ), or no or only minimal additional benefit. The overall additional benefit provided by an intervention is based on the assessments for the above listed categories [70]. Neither the IQWiG nor the G-BA have published a definitive algorithm determining the additional benefit.

The assessment methods used by this and other HTA institutions do not differentiate between different medical specialties. They use no special methods or parameters to assess systemic oncologic therapies [48-50].

However, two well-known medical societies recently developed tools which aim to provide a standardized and systematic evaluation of the clinical benefit of new systemic oncologic therapies. These tools are the Value Framework of the ASCO and the Medical Oncology Magnitude Clinical Benefit Scale (MCBS) of the ESMO [1,2].

To assess adjuvant therapies, the ASCO uses the hazard ratio for OS and compares the new therapy with a control therapy. If the HR for OS is not reported, the ASCO uses the HR for DFS. The hazard ratio is classified into 1 of 5 categories depending on the magnitude of the HR. The maximum score is 80 points. A therapy with a HR for DFS $>0.85$ will receive 0 points, a therapy with a HR for DFS of between 0.84 and 0.71 is given 15 points, and a therapy with a $\mathrm{HR}<0.20$ will achieve 80 points. In a second step, the difference between the two therapies with regard to grade 3-5 toxicity is also assigned to one of 5 categories. The score for toxicity difference ranges from +20 for significantly lower toxicity to -20 for significantly higher toxicity. The final score calculated from the two scales is known as the net health benefit (NHB); the maximum possible number of points is 100 . The final score for the therapy is reported descriptively as $\mathrm{x}$ number of points out of a maximum possible number of 100 points together with the costs of the new medication in the USA. No threshold values for a clinically relevant benefit are defined and no evaluations are made [1].

The ESMO developed and validated the MCBS as a tool to determine the clinical benefit of new systemic therapies. In contrast to the tool described above, the MCBS evaluates clinical benefit in terms of clinical relevance. Three categories - A, B and C - are used to evaluate adjuvant therapies. Category $C$ indicates that there is no clinically relevant benefit. The classification is based on the benefits of the new therapy with regard to the endpoints OS or DFS, if OS is not available. Toxicity, quality of life and costs of therapy are included in the assessment if the new therapy is shown to be not inferior with regard to OS and DFS ( $\bullet$ Fig. 1). The highest clinically relevant benefit (grade A) is achieved if the absolute improvement in mortality after at least 3 years is more than $5 \%$. If the OS data is immature, there must be a significant improvement in DFS with a lower limit of the $95 \%$ confidence interval $(\mathrm{Cl})$ of less than 0.65 to achieve grade $\mathrm{A}$. A clinically relevant benefit for the second highest category $B$ is present if there is an absolute improvement in mortality after at least 3 years of $3-5 \%$. If the OS is immature, a significant improvement in DFS where the lower limit of the $95 \% \mathrm{Cl}$ is $0.65-0.8$ is required to achieve 
grade $B$. If OS and DFS of the new therapy are not inferior to those of controls in non-inferiority studies, then the new therapy must additionally show either reduced toxicity or better quality of life or the costs of treatment must be lower for the new therapy to be categorized as offering a clinically relevant benefit (grade B) [2].

\section{Summary and Conclusions}

The goal of adjuvant therapy is to improve curative options even further.

Given the above stated aim, assessment of the clinical benefit of an adjuvant therapy for early breast cancer is largely based on efficacy endpoints, although findings for toxicity and quality of life are also taken into account when deciding for or against a specific adjuvant therapy.

Because the mortality rate has decreased significantly in recent years, a benefit in terms of overall survival can only be determined after many years of follow-up. Disease-free survival, which has been accepted as a surrogate marker for overall survival $[2,71,72]$, has therefore become more important for the assessment of treatment modalities $[1,2,12,13]$. In a curative setting, a relapse with recurrence of disease is per se a relevant event for the patient.

The evidence from existing adjuvant therapy standards provides a good scale against which the clinical benefit of new adjuvant therapies for patients with early breast cancer can be measured. It is important to remember, however, that the benefit of established adjuvant therapies in terms of reduced risk of recurrence only began to emerge after 2 to 3 years of follow-up and continued to increase until 5 years of follow-up [28-30,32]. The introduction of the therapeutic principles of adjuvant endocrine therapy, polychemotherapy and anti-HER2 therapy led to a reduction in the risk of recurrence by $30-50 \%$. Absolute differences in recurrence risk after 5 years were $11.4 \%$ [23, 28 - 30,32]. Current therapy standards such as chemotherapy with anthracyclines and taxanes or endocrine therapy with aromatase inhibitors over a period of 5 years are further developments of the principles of adjuvant therapy. They have led to more moderate reductions in the recurrence risk of $11-16 \%$ and $18-30 \%$. The absolute improvement after 5 years was 3.6\% [28-32]. The MCBS of the ESMO requires improvements of a similar magnitude. However, the MCBS does not use absolute improvements measured at specific timepoints to assess DFS but uses the hazard ratio instead. According to the MCBS, a new adjuvant therapy offers a clinical benefit if the lower limit of the $95 \% \mathrm{CI}$ for DFS is < 0.8 [2]. It should also be mentioned that improvements of this magnitude reported for taxanes and aromatase inhibitors provided the basis for the approval of these treatment modalities and led to their inclusion in guideline recommendations [73-75].

In consequence, new drugs to treat patients with early breast cancer should be considered as offering a clinical benefit if they lead a further reduction in the risk of recurrence and the magnitude of the reduction corresponds to that of current therapy standards. After a lengthy period of follow-up the reduction in recurrence risk should also translate into a survival benefit without the patient suffering a lasting adverse effect from toxicities.

Ultimately the question regarding the clinical relevance of a new therapy must be answered individually for every patient.
There is a considerable difference in expectations. A German study which surveyed 2155 patients and 527 physicians highlighted the breadth of expectations and the extent of the discrepancy between the expectations of patients and those of their physicians with regard to the benefit of adjuvant therapies. One third of patients and a considerable percentage of physicians had unrealistic assumptions about the expected increases in 5-year survival rates following adjuvant chemotherapy, endocrine therapy or antibody therapy [76]. Because of this, when making an informed decision it is useful to consider the expected benefit in the context of the parameters used to assess established therapy standards.

\section{Conflict of Interest}

Volker Möbus was a consultant for Amgen, Celgene and Roche and has received consulting fees from Amgen and Celgene. Susanne Hell has received consulting fees from Genomic Health and is employed by Roche Pharma AG. Marcus Schmidt was a consultant for Astra Zeneca, Celgene, Eisai, Myriad, Novartis, Pfizer, Pierre-Fabre, Roche, Sividon and has also received consulting fees from these companies.

\section{Update (13.11.2017)}

In the meantime an updated version 1.1 of the ESMO MCBS was published. For new approaches to adjuvant or potentially curative therapies a clinical benefit of Grade $C$ is also assigned based on improvements in pathologic complete response rate ( $P C R)$ alone, if primary endpoint, by $\geq 30 \%$ relative and $\geq 15 \%$ absolute gain in studies without mature survival data [Cherny NI, Dafni U, Bogaerts J et al. ESMO-Magnitude of Clinical Benefit Scale version 1.1. Ann Oncol 2017; 28: 2340-2366]. Otherwise all statements in this review paper regarding the ESMO MCBS still apply.

\section{References}

[1] Schnipper LE, Davidson NE, Wollins DS et al. American Society of Clinical Oncology statement: a conceptual framework to assess the value of cancer treatment options. J Clin Oncol 2015; 33: 2563-2577

[2] Cherny NI, Sullivan R, Dafni U et al. A standardised, generic, validated approach to stratify the magnitude of clinical benefit that can be anticipated from anti-cancer therapies: the European Society for Medical Oncology Magnitude of Clinical Benefit Scale (ESMO-MCBS). Ann Oncol 2015; 26: 1547-1573

[3] Chan A, Delaloge S, Holmes FA et al. Neratinib after trastuzumab-based adjuvant therapy in patients with HER2-positive breast cancer (ExteNET): a multicentre, randomised, double-blind, placebo-controlled, phase 3 trial. Lancet Oncol 2016; 17: 367-377

[4] Von Minckwitz G, Procter M], De Azambuja E et al. Adjuvant pertuzumab and trastuzumab in early HER2-positive breast cancer. N Engl J Med 2017; 377: 122-131

[5] Clinicaltrial.gov. NCT02513394. Online: https://clinicaltrials.gov/ct2/ show/NCT02513394?term=palbociclib+adjuvant\&cond=breast + cancer\&rank=1; last access: 16.08.2017

[6] Clinicaltrial.gov. NCT03078751. Online: https://clinicaltrials.gov/ct2/ show/NCT03078751?term=ribociclib+adjuvant\&cond=breast+cancer \&rank=1; last access: 16.08.2017

[7] Clinicaltrial.gov. NCT03081234. Online: https://clinicaltrials.gov/ct2/ show/NCT03081234?term=ribociclib+adjuvant\&cond=breast+cancer \&rank=2; last access: 16.08.2017 
[8] Clinicaltrial.gov. NCT03155997. Online: https://clinicaltrials.gov/ct2/ show/NCT03155997?term=abemaciclib+adjuvant\&cond=breast + cancer\&rank=1; last access: 16.08.2017

[9] Clinicaltrial.gov. NCT02954874. Online: https://clinicaltrials.gov/ct2/ show/NCT02954874?term=pembrolizumab+adjuvant\&cond=breast + cancer\&rank=2; last access: 16.08.2017

[10] Clinicaltrial.gov. NCT03036488. Online: https://clinicaltrials.gov/ct2/ show/NCT03036488?term=pembrolizumab+adjuvant\&cond=breast ${ }^{+}$ cancer\&rank=1; last access: 16.08 .2017

[11] Clinicaltrial.gov. NCT02926196. Online: https://clinicaltrials.gov/ct2/ show/NCT02926196?term=avelumab+adjuvant\&cond=breast+cancer \&rank $=1$; last access: 16.08 .2017

[12] FDA Guidance for industry: cinical trial endpoints for the approval of cancer drugs and biologicals, May 2007. Online: https://www.fda.gov/ downloads/drugsGuidanceComplianceRegulatoyInformation/Guidance/ UCM071590.pdf; last access: 16.08.2017

[13] EMA Guideline on the evaluation of anticancer medicinal products in man, December 2012. Online: http://www.ema.europa.eu/docs/en_GB /document_library/Scientific_guideline/2013/01/WC500137128.pdf; last access: 16.08.2017

[14] Goldhirsch A, Winer EP, Coates AS et al. Personalizing the treatment of women with early breast cancer: highlights of the St Gallen International Expert Consensus on the Primary Therapy of Early Breast Cancer 2013. Ann Oncol 2013; 24: 2206-2223

[15] Coates AS, Winer EP, Goldhirsch A et al. Tailoring therapies - improving the management of early breast cancer: St Gallen International Expert Consensus on the Primary Therapy of Early Breast Cancer 2015. Ann Oncol 2015; 26: 1533-1546

[16] Senkus E, Kyriakides S, Ohno S et al. Primary breast cancer: ESMO Clinical Practice Guidelines for diagnosis, treatment and follow-up. Ann Oncol 2015; 26 (Suppl. 5): v8-v30

[17] Deutsche Krebsgesellschaft e.V. (DKG). Interdisziplinäre S3-Leitlinie für die Diagnostik, Therapie und Nachsorge des Mammakarzinoms. Langversion 3.0, Aktualisierung 2012. AWMF-Register-Nummer: 032 -045OL [online]. Stand: 07.2012. Online: http://www.awmf.org/leitlinien/detail/ II/032-045OL.html; last access: 16.08.2017

[18] Arbeitsgemeinschaft Gynäkologische Onkologie e.V. (AGO). Diagnostik und Therapie von Patientinnen mit primärem und metastasiertem Brustkrebs [online]. Stand: 02.03.2017. Online: http://www.ago-online.de/ fileadmin/downloads/leitlinien/mamma/2017-03/AGO_deutsch/PDF_ Gesamtdatei_deutsch/Alle_aktuellen_Empfehlungen_2017.pdf; last access: 16.08 .2017

[19] Deutsche Gesellschaft für Hämatologie und Medizinische Onkologie e.V. (DGHO). Mammakarzinom der Frau. Leitlinie [online]. Stand: 04.2017. Online: https://www.onkopedia.com/de/onkopedia/guidelines/ mammakarzinom-der-frau/@@view/html/index.html; last access: 16.08.2017

[20] Mieog JS, van der Hage JA, van de Velde C]. Preoperative chemotherapy for women with operable breast cancer. Cochrane Database Syst Rev 2007; (2): CD005002

[21] Mauri D, Pavlidis N, loannidis JP. Neoadjuvant versus adjuvant systemic treatment in breast cancer: a meta-analysis. J Natl Cancer Inst 2005; 97 : 188-194

[22] Robert Koch-Institut. Bericht zum Krebsgeschehen in Deutschland 2016. Online: http://www.krebsdaten.de/Krebs/DE/Content/Publikationen/ Krebsgeschehen/Krebsgeschehen_download.pdf?__blob=publication File; last access: 16.08.2017

[23] Moja L, Tagliabue L, Balduzzi S et al. Trastuzumab containing regimens for early breast cancer. Cochrane Database Syst Rev 2012; (4): CD006243

[24] Cameron D, Piccart-Gebhart M], Gelber RD et al. 11 years' follow-up of trastuzumab after adjuvant chemotherapy in HER2-positive early breast cancer: final analysis of the HERceptin Adjuvant (HERA) trial. Lancet 2017; 389: 1195-1205
[25] Perez EA, Romond EH, Suman V] et al. Trastuzumab plus adjuvant chemotherapy for human epidermal growth factor receptor 2-positive breast cancer: planned joint analysis of overall survival from NSABP B31 and NCCTG N9831. J Clin Oncol 2014; 32: 3744-3752

[26] Slamon DJ, Eiermann W, Robert NJ et al. Ten year follow-up of BCIRG-006 comparing doxorubicin plus cyclophosphamide followed by docetaxel $(\mathrm{AC} \rightarrow \mathrm{T})$ with doxorubicin plus cyclophosphamide followed by docetaxel and trastuzumab $(\mathrm{AC} \rightarrow \mathrm{TH})$ with docetaxel, carboplatin and trastuzumab (TCH) in HER2+ early breast cancer. SABCS 2015; Abstr. S5-04

[27] Roche data on file

[28] Early Breast Cancer Trialist Collaborative Group. Tamoxifen for early breast cancer: an overview of the randomised trials. Lancet 1998; 351 : 1451-1467

[29] Early Breast Cancer Trialist Collaborative Group. Effects of chemotherapy and hormonal therapy for early breast cancer on recurrence and 15-year survival: an overview of the randomized trials. Lancet 2005; 365: 16871717

[30] Early Breast Cancer Trialist Collaborative Group. Aromatase inhibitors versus tamoxifen in early breast cancer: patient-level meta-analysis of the randomized trials. Lancet 2015; 386: 1341-1352

[31] Aydiner A. Meta-analysis of breast cancer outcome and toxicity in adjuvant trials of aromatase inhibitors in postmenopausal women. Breast 2013; 22: 121-129

[32] Early Breast Cancer Trialist Collaborative Group. Comparisons between different polychemotherapy regimens for early breast cancer: metaanalyses of long-term outcome among 100000 women in 123 randomised trials. Lancet 2012; 379: 432-444

[33] Bonnadonna G, Brusamolino E, Valgussa P et al. Combination chemotherapy as an adjuvant treatment in operable breast cancer. $\mathrm{N}$ Engl J Med 1976; 294: 405-410

[34] Bria E, Nistico C, Cuppone F et al. Benefit of taxanes as adjuvant chemotherapy for early breast cancer: pooled analysis of 15,500 patients. Cancer 2006; 106: 2337-2344

[35] Ferguson T, Wilcken N, Vagg R et al. Taxanes for adjuvant treatment of early breast cancer. Cochrane Database Syst Rev 2007; (4): CD004421

[36] De Laurentiis M, Cancello G, D’Agostino D et al. Taxane-based combinations as adjuvant chemotherapy of early breast cancer: a meta-analysis of randomized trials. J Clin Oncol 2008; 26: 44-53

[37] Jacquin JP, Jones S, Magné $\mathrm{N}$ et al. Docetaxel-containing adjuvant chemotherapy in patients with early stage breast cancer. Consistency of effect independent of nodal and biomarker status: a meta-analysis of 14 randomized clinical trials. Breast Cancer Res Treat 2012; 134: 903-913

[38] Qin YY, Li H, Guo X] et al. Adjuvant chemotherapy, with or without taxanes, in early or operable breast cancer: a meta-analysis of 19 randomized trials with 30698 patients. PLoS One 2011; 6: e26946

[39] Viani GA, Afonso SL, Stefano EJ et al. Adjuvant trastuzumab in the treatment of her-2-positive early breast cancer: a meta-analysis of published randomized trials. BMC Cancer 2007; 7: 153

[40] Dahabreh IJ, Linardou H, Siannis F et al. Trastuzumab in the adjuvant treatment of early-stage breast cancer: a systematic review and metaanalysis of randomized controlled trials. Oncologist 2008; 13: 620-630

[41] Yin W, Jiang Y, Shen Z et al. Trastuzumab in the adjuvant treatment of HER2-positive early breast cancer patients: a meta-analysis of published randomized controlled trials. PLoS One 2011; 6: e21030

[42] Jackisch C, Piccart MJ, Gelber RD et al. HERA trial: 10 years follow up of trastuzumab after adjuvant chemotherapy in HER2 positive early breast cancer - Final analysis. SABCS 2015; Abstr. PD5-01

[43] Slamon D, Eiermann W, Robert $N$ et al. Adjuvant trastuzumab in HER2positive breast cancer. N Engl J Med 2011; 365: 1273-1283

[44] Bonilla L, Ben-Aharon I, Vidal L et al. Dose-dense chemotherapy in nonmetastatic breast cancer: a systematic review and meta-analysis of randomized controlled trials. J Natl Cancer Inst 2010; 102: 1845-1854 
[45] Lemos Duarte I, da Silveira Nogueira Lima JP, Passos Lima CS et al. Dosedense chemotherapy versus conventional chemotherapy for early breast cancer: a systematic review with meta-analysis. Breast 2012; 21: $343-$ 349

[46] Petrelli F, Cabiddu M, Coinu A et al. Adjuvant dose-dense chemotherapy in breast cancer: a systematic review and meta-analysis of randomized trials. Breast Cancer Res Treat 2015; 151: 251-259

[47] Möbus V. Adjuvant dose-dense chemotherapy in breast cancer: standard of care in high-risk patients. Breast Care (Basel) 2016; 11: 8-12

[48] Moebus V, Jackisch C, Lueck HJ et al. Intense dose-dense sequential chemotherapy with epirubicin, paclitaxel, and cyclophosphamide compared with conventionally scheduled chemotherapy in high-risk primary breast cancer: mature results of an AGO phase III study. J Clin Oncol 2010; 28: 2874-2880

[49] Moebus V, Jackisch C, Lueck HJ et al. Ten-year follow-up analysis of intense dose-dense adjuvant ETC (epirubicin (E), paclitaxel $(\mathrm{T})$ and cyclophosphamide (C) confirms superior DFS and OS benefit in comparison to conventional dosed chemotherapy in high-risk breast cancer patients with $\geq 4$ positive lymph nodes. SABCS 2012; Abstr. S3-04

[50] Tolaney SM, Barry WT, Guo H et al. Seven-year (yr) follow-up of adjuvant paclitaxel (T) and trastuzumab (H) (APT trial) for node-negative, HER2positive breast cancer (BC). J Clin Oncol 2017; 35 (no. 15_suppl): 511

[51] Schmidt M, Thomssen C, Untch M. Intrinsic subtypes of primary breast cancer-gene expression analysis. Oncol Res Treat 2016; 39: 102-110

[52] Filipits M, Rudas M, Jakesz R et al. A new molecular predictor of distant recurrence in ER-positive, HER2-negative breast cancer adds independent information to conventional clinical risk factors. Clin Cancer Res 2011; 17: 6012-6020

[53] Dubsky P, Brase JC, Jakesz R et al. The EndoPredict score provides prognostic information on late distant metastases in ER+/HER2- breast cancer patients. Br J Cancer 2013; 109: 2959-2964

[54] Dubsky P, Filipits M, Jakesz R et al. EndoPredict improves the prognostic classification derived from common clinical guidelines in ER-positive, HER2-negative early breast cancer. Ann Oncol 2013; 24: 640-647

[55] Martin M, Brase JC, Calvo L et al. Clinical validation of the EndoPredict test in node-positive, chemotherapy-treated ER+/HER2- breast cancer patients: results from the GEICAM 9906 trial. Breast Cancer Res 2014; 16: R38

[56] Paik S, Shak S, Tang G et al. A multigene assay to predict recurrence of tamoxifen-treated, node-negative breast cancer. N Engl J Med 2004; 351: 2817-2826

[57] Paik S, Tang G, Shak S et al. Gene expression and benefit of chemotherapy in women with node-negative, estrogen receptor-positive breast cancer. J Clin Oncol 2006; 24: 3726-3734

[58] Albain KS, Barlow WE, Shak S et al. Prognostic and predictive value of the 21-gene recurrence score assay in 16 postmenopausal women with node-positive, oestrogen-receptor-positive breast cancer on 17 chemotherapy: a retrospective analysis of a randomised trial. Lancet Oncol 2010; 11: 55-65

[59] Sgroi DC, Sestak I, Cuzick J et al. Prediction of late distant recurrence in patients with oestrogen-receptor-positive breast cancer: a prospective comparison of the breast-cancer index $(\mathrm{BCl})$ assay, 21-gene recurrence score, and IHC4 in the TransATAC study population. Lancet Oncol 2013; 14: 1067-1076

[60] Wolmark N, Mamounas EP, Baehner FL et al. Prognostic impact of the combination of recurrence score and quantitative estrogen receptor expression (ESR1) on predicting late distant recurrence risk in estrogen receptor-positive breast cancer after 5 years of tamoxifen: results from NRG Oncology/National Surgical Adjuvant Breast and Bowel Project B-28 and B-14. J Clin Oncol 2016; 34: 2350-2358

[61] Martin M, Rodríguez-Lescure A, Caballero R et al. PAM50 proliferation score as a predictor of weekly paclitaxel benefit in breast cancer. Breast Cancer Res Treat 2013; 138: 457-466
[62] Filipits M, Nielsen TO, Rudas M et al. The PAM50 risk-of-recurrence score predicts risk for late distant recurrence after endocrine therapy in postmenopausal women with endocrine-responsive early breast cancer. Clin Cancer Res 2014; 20: 1298-1305

[63] Gnant M, Filipits M, Greil R et al. Predicting distant recurrence in receptor-positive breast cancer patients with limited clinicopathological risk: using the PAM50 Risk of Recurrence score in 1478 postmenopausal patients of the ABCSG-8 trial treated with adjuvant endocrine therapy alone. Ann Oncol 2014; 25: 339-345

[64] Gnant M, Sestak I, Filipits M et al. Identifying clinically relevant prognostic subgroups of postmenopausal women with node-positive hormone receptor-positive early-stage breast cancer treated with endocrine therapy: a combined analysis of ABCSG-8 and ATAC using the PAM50 risk of recurrence score and intrinsic subtype. Ann Oncol 2015; 26: 1685-1691

[65] Gluz O, Nitz UA, Christgen M et al. West German Study Group Phase III PlanB Trial: first prospective outcome data for the 21 -gene recurrence score assay and concordance of prognostic markers by central and local pathology assessment. J Clin Oncol 2016; 34: 2341-2349

[66] Sparano JA, Gray RJ, Makower DF et al. Prospective validation of a 21gene expression assay in breast cancer. N Engl J Med 2015; 373: 20052014

[67] Cardoso F, van't Veer L], Bogaerts ] et al. 70-gene signature as an aid to treatment decisions in early-stage breast cancer. N Engl J Med 2016; 375: 717-729

[68] National Institute for Health and Care Excellence NICE. Guide to the methods of technology appraisal 2013, published date: April 2013. Online: https://www.nice.org.uk/process/pmg9/chapter/foreword; last access: 16.08 .2017

[69] Haute Authorité de Santé. Methods and criteria for assessing medicinal products. Stand Oktober 2015. Online: https://www.has-sante.fr/portail /jcms/c_2035651/en/methods-and-criteria-for-assessing-medicinalproducts; last access: 16.08.2017

[70] Institut für Qualität und Wirtschaftlichkeit im Gesundheitswesen. Allgemeine Methode, Version 5.0 vom 10.07.2017. Online: https://www. iqwig.de/download/Allgemeine-Methoden_Version-5-0.pdf; last access: 16.08 .2017

[71] Deutsche Gesellschaft für Hämatologie und Onkologie (DGHO). Frühe Nutzenbewertung onkologischer Arzneimittel: Diskussionspapier der DGHO zu den Fragen des Gemeinsamen Bundesausschusses anlässlich der Diskussionsrunde am 29. November 2010. Online: https://www. g-ba.de/downloads/17-98-3003/DGHO.pdf; last access: 16.08.2017

[72] Gill S, Sargent D. End points for adjuvant therapy trials: has the time come to accept disease-free survival as a surrogate end point for overall survival? Oncologist 2006; 11: 624-629

[73] European Medicines Agency (EMA). Medical assessment report for Taxotere vom 20.05.2010, Doc. Ref No.: EMA/355802/2010. Stand: 20.05.2010. Online: http://www.ema.europa.eu/docs/en_GB/ document_library/EPAR_-_Assessment_Report_-_Variation/human/ 000073/WC500095365.pdf; last access: 16.08.2017

[74] Food and Drug Administration (FDA). Medical Review Arimidex (anastrozole) ZD1033, NDA Number: 20,541, Efficacy Supplement Clinical Review vom 28. August 2002. Stand: 28.08.2002. Online: http://www. accessdata.fda.gov/drugsatfda_docs/nda/2002/20-541S010_Arimidex_ medr_P1.pdf; last access: 31.03.2017

[75] Food and Drug Administration (FDA). Medical Review Taxotere (Docetaxel) sNDA Numer 20,449 Efficacy Supplement Clinical Review vom 17. August 2004. Stand: 17.08.2004. Online: http://www.accessdata. fda.gov/drugsatfda_docs/nda/2004/20-449s029_Taxotere_medr.PDF; last access: 16.08 .2017

[76] Thiel FC, Schrauder MG, Fasching PA et al. Shared decision-making in breast cancer: discrepancy between the treatment efficacy required by patients and by physicians. Breast Cancer Res Treat 2012; 135: 811-820 